\title{
A Spectrum of Wild Animal Related Injuries in the Sub Himalayan Terrain of North Bengal
}

\author{
Dwaipayan Samaddar ${ }^{1}$, Jaya Bagchi-Samaddar², Partha Pratim Sinha Roy ${ }^{3}$, Gautam Das ${ }^{4}$ \\ ${ }^{1}$ Department of General Surgery, North Bengal Medical College and Hospital, Siliguri, West Bengal, India. \\ ${ }^{2}$ Department of Pathology, Islampur Sub-Divisional Hospital, Uttar Dinajpur, West Bengal, India. \\ ${ }^{3}$ Department of General Surgery, ESI-PGIMSR, ESIC Medical College and Hospital, Kolkata, West Bengal, \\ India. ${ }^{4}$ Department of General Surgery, IPGME\&R and SSKM Hospital, Kolkata, West Bengal, India.
}

\section{ABSTRACT}

\section{BACKGROUND}

Wild animal related injury is a serious health problem for people living in the foothills of the sub Himalayan terrain. Geographically the foothills are proximal to the tea gardens and the dense forests which in turn are in close proximity to human habitation. Thus, the tea garden workers and labourers as well as others are always at imminent threat from the abundant wildlife. The type of injury could be quite serious, sometimes grotesque and even life threatening. Though we regularly face various kinds of such injuries inflicted from wild animals, there are no studies regarding this very pertinent problem at hand. We wanted to evaluate the causes and treatment outcomes of wild animal injuries in the foothills of sub Himalayan terrain.

\section{METHODS}

This is a descriptive study conducted for a period of two years. We reviewed the medical records of about 103 patients with wild animal related injuries in North Bengal Medical College and Hospital, between July 2017 to May 2019. Data was collected and compiled in Excel sheet followed by analysis using software Epi Info and Epi Calc 2000.

\section{RESULTS}

The medical records of about 103 patients with wild animal related injuries in a rural tertiary medical college and hospital of North Bengal between July 2017 to May 2019 were reviewed. Demographic and etiological characteristics of patients and injury and outcome data were analysed. $80 \%$ were males and $20 \%$ females. The mean age was 33 years (13-77 years). 80\% were inflicted by elephants. However, a wide array of animals like rhinos, leopards, bison and leopards were responsible. There were eleven deaths, elephant trampling accounting for nine of them. Interestingly there were urban victims too.

\section{CONCLUSIONS}

Wild animal related injuries constitute an important public health problem for people living in this sub-Himalayan belt which needs to be addressed with proper environmental and health measures.

\section{KEY WORDS}

Wild Animal Injuries, Public Health, Rural Areas
Corresponding Author: Dr. Partha Pratim Sinha Roy, \#15, New Santoshpur, First Lane, Kolkata-700075, West Bengal, India.

E-mail:ppsr88@gmail.com

DOI: $10.14260 / \mathrm{jemds} / 2020 / 126$

Financial or Other Competing Interests: None.

How to Cite This Article:

Samaddar D, Bagchi-Samaddar J, Sinha Roy-PP, et al. A spectrum of wild animal related injuries in the sub Himalayan terrain of North Bengal. J. Evolution Med. Dent. Sci.2020;9(08):566-569, DOI: 10.14260/jemds/2020/126

Submission 19-12-2019, Peer Review 28-01-2020, Acceptance 05-02-2020, Published 24-02-2020.

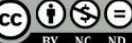




\section{BACKGROUND}

The state of West Bengal stretches over an area of 88752 sq. $\mathrm{Km}$., out of which $13.38 \%$ includes recorded forest category. The northern part of West Bengal covering the Dooars and Terai regions includes three districts viz. Jalpaiguri, Darjeeling and Cooch Behar. The total forest areas recorded are 1790 sq. Km., 1204 sq.Km. and 57 sq.Km respectively.[1] The recent wildlife census records 255 rhinos (2015), 3 Bengal tigers, 782 bison, 590+ elephants (2014), 105+ leopards (2012) in the Northern Bengal forests.[2]

Human Animal Conflicts (HAC) arises from negative interactions between humans and wildlife, both directly and indirectly. [3] Human - wildlife conflict can be defined as "any interaction between human and wildlife that results in negative impacts on human social, economic or cultural life, on the conservation of wildlife populations, or on the environment." ${ }^{[4]}$ The conflict eventually results in detrimental effects on both wild animals as well as humans. Apart from economic losses suffered by the human population like destruction of agricultural crops, loss of cattle through predation by carnivores, damage to immovable properties etc. mortality on both sides take the extreme form in these conflict scenarios. Along with wildlife, each year huge number of human life is lost place in these fall-outs.

\section{Reasons for HAC}

Each animal species requires a specific habitat consisting of a single type or mixed vegetation providing all necessary resources for survival. In recent years HAC has gone up steeply owing to-

- Increase in human population.

- Land use transformations.

- Developmental activities.

- Species habitat degradation and fragmentation.

- Growing interest in ecotourism and increasing access to nature reserves.

- Increasing livestock population and competitive exclusion of wild herbivores.

- Stochastic events like fire.

- Most importantly, increasing wildlife population as a result of conservation strategies.

Wild animal related injuries (WARI) are common and are an important health problem for people living in the sub Himalayan terrain of North Bengal. Patients with wild animal trauma may present with blunt and penetrating high energy transfer injuries to multiple body areas.[5] Serious injuries were caused mostly by elephants. However other animals like rhinos, leopards, bison and wild boars were also culprits. Our institute located in the foothills of the Himalayas is in close vicinity to many jungles that have been subjected to deforestation over a prolonged time period as a fallout of socio-economic development in the form of tea plantations of the nearby towns. This has brought the wild animals closer to human habitat. Our institute is the only tertiary care centre in this region catering to the hilly regions of Darjeeling, Sikkim and also the border state of Bihar. We even cater to neighbouring countries Nepal and Bangladesh and Bhutan because of the close geographical proximity. Though animal husbandry is quite common in these areas the majority of reported injuries are due to wild animals rather than domestic.

The aim of this study was to analyse a series of 103 patients who were treated for WARI over the last 2 years. Also, the predominance of wild animal injuries in this geographical area and the lack of any such study in this area prompted us to carry out this study.

\section{METHODS}

Total number of cases studied was 103 which include all the patients attending the OPD and IPD of department of general surgery of North Bengal Medical College and Hospital after sustaining any type of injury by wild animals between June 2017 to May 2019. Approval from Institutional Ethics Committee was taken. Informed consent from all the patients or guardian of the patient was taken, confidentiality of the findings of the patients was ensured and data was utilised purely for academic purpose. Detailed demographic and etiological characteristics of patients and injury were recorded using a preformed data collection form and analysed thoroughly. Each patient was thoroughly examined clinically, and relevant investigations were done.

The patients were provided the standard treatment modalities available in the rural tertiary care hospital. The outcome of the treatment was evaluated.

The data collected were first charted in Excel sheet. Then analysed by Z-test and p-value was calculated. Categorical variables are expressed as number of patients and percentage of patients and compared using Z-test. The statistical software Epi Info and Epi Calc 2000 had been used for analysis. An alpha level of $5 \%$ had been taken, i.e. if any pvalue was less than 0.05 it had been considered as significant.

\section{RESULTS}

A total of 103 patients were included in the study. Of them 66 were male and 37 were female ( $p$ value $<0.001$ ). The mean age was 39.9 years (range 11-62 years). Most of the patients were victims to elephants $(36.9 \%)$ followed by tigers $(22.3 \%)$. Nature of injuries were mostly bite injuries (36.9\%) followed by trampling (23.3\%). Six (5.82\%) of our patients had multiple organ injuries (table-1). Most patients were hospitalized $(70.9 \%)$ and $24(23.3 \%)$ required surgery. 12 (11.6\%) patients underwent CT scan of abdomen or head. Most of the patients had extremity injuries (56.4\%) followed by maxillofacial $(19.4 \%)$. Location of injuries are shown in Table- 2. The patients managed non-operatively in the IPDs generally had soft tissue injuries and trivial chest injuries that were tackled without the need for a formal thoracotomy. Physical signs of acute abdomen (tenderness, muscle guarding and rigidity) were observed in 12 (11.6\%) patients. CT abdomen was performed on 1 patient and MRI dorsolumbar spine was performed on 1 patient whereas USG abdomen was performed on 10 patients.

Among the operated patients 4 (3.9\%) had postoperative complications mainly surgical site infections and atelectasis. All were treated conservatively. 2 (1.9\%) patients developed paraparesis due to inflicted spinal injury by elephant. 
Diagnostic and treatment modalities performed are depicted in Table- 3. Deaths were 11 (10.6\%) out of which 9 (2.9\%) had severe traumatic brain injuries and other 2 succumbed to great vessel injuries. Elephants trampled 9 (8\%) of the above 11 to death while a rhino and a wild boar accounted for the other two.

All the patients received active and passive (where needed) immunization for tetanus. Also, anti-rabies vaccine was administered when indicated, chiefly in bites.

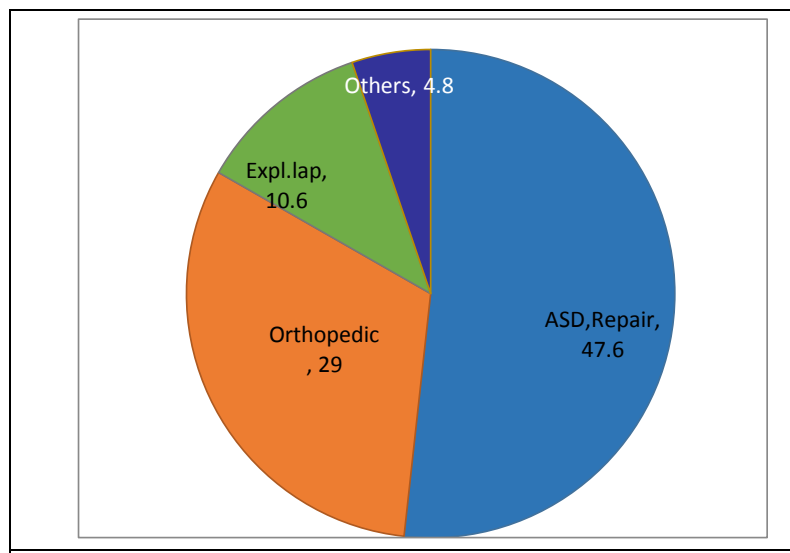

Figure 1. Percentage of Different Modes of Treatment Provided

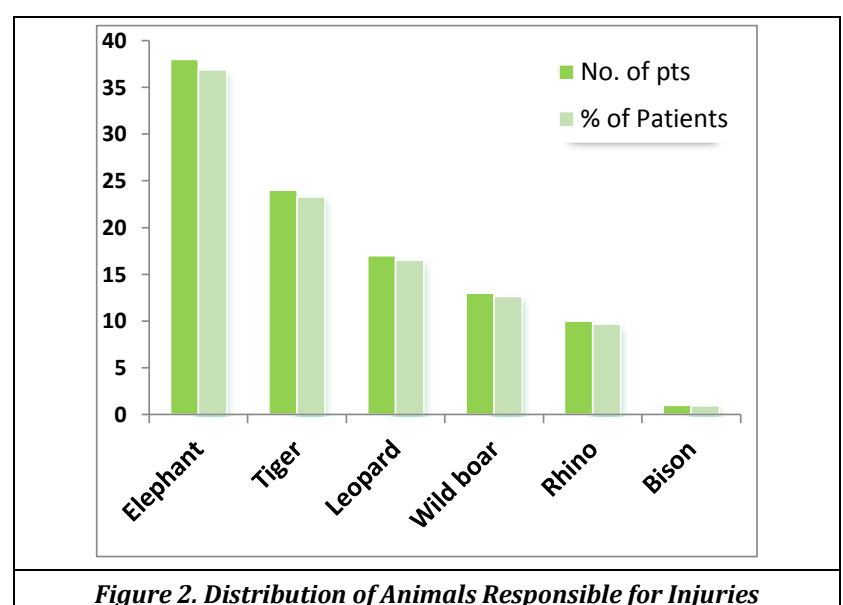

Figure 2. Distribution of Animals Responsible for Injuries

\begin{tabular}{|c|c|c|c|}
\hline Demography, Causes and Type of Injury & Number of Patients & $\mathbf{\%}$ \\
\hline \multirow{4}{*}{ Gender } & Male & 66 & $64.07 \%$ \\
\cline { 2 - 4 } & Female & 37 & $35.92 \%$ \\
\hline \multirow{4}{*}{ Cause of injury } & Elephant & 38 & $36.89 \%$ \\
\cline { 2 - 4 } & Tiger & 24 & $23.30 \%$ \\
\cline { 2 - 4 } & Leopard & 17 & $16.50 \%$ \\
\cline { 2 - 4 } & Wild boar & 13 & $12.62 \%$ \\
\cline { 2 - 4 } & Rhino & 10 & $09.70 \%$ \\
\cline { 2 - 4 } & Bison & 01 & $0.97 \%$ \\
\hline \multirow{5}{*}{ Type of injury } & Bite & 38 & $36.89 \%$ \\
\cline { 2 - 4 } & Trampling & 26 & $25.24 \%$ \\
\cline { 2 - 4 } & Gore & 24 & $23.30 \%$ \\
\cline { 2 - 4 } & Throw & 10 & $09.70 \%$ \\
\cline { 2 - 4 } & Claw & 03 & $02.91 \%$ \\
\cline { 2 - 4 } & Kick & 01 & $0.97 \%$ \\
\cline { 2 - 4 } & Tusked & 01 & $0.97 \%$ \\
\hline \multirow{7}{*}{ Treatment } & OPD & 30 & $90.12 \%$ \\
\cline { 2 - 4 } & IPD & 73 & $04.17 \%$ \\
\hline \multirow{4}{*}{ Number of organ injuries } & Single & 97 & $06.82 \%$ \\
\cline { 2 - 4 } & 2 & 06 & \\
\hline
\end{tabular}

Table 1. Distribution of Injuries According to Demography, Causes and Type of Injuries

\begin{tabular}{|c|c|c|}
\hline Trauma Localisation & Number of Patients & Percentage \\
\hline Maxillofacial & 22 & $21.35 \%$ \\
\hline Extremity & 57 & $55.33 \%$ \\
\hline Craniospinal & 09 & $08.73 \%$ \\
\hline Thorax & 09 & $08.73 \%$ \\
\hline Abdominal & 14 & $13.60 \%$ \\
\hline Table 2. Distribution of Most Pertinent Injuries According to Location \\
\hline
\end{tabular}

\section{DISCUSSION}

Wild animal inflicted injuries are showing an increasing trend worldwide though the exact incidence is not known.[6] The study of Rasouli et al revealed that around $1 \%$ of the cases admitted in the emergency room had animal related injuries and mortality in them is $0.2 . \%$.[7] Animal inflicted injuries generally affects young population and more commonly males. ${ }^{[8,9]}$ The average age in the study conducted by John's et al is $34,{ }^{[10]}$ by Temes et al is 27.[11] and Brett et al is 32,,12] Watts and Meisel is 34[13] and Kousuke et al is 30.[14] Similar results were demonstrated in our study with a mean age of 39.9 years. The study conducted by Yildiz et al[15] 13 of 19 patients were male. Moini et al demonstrated a male preponderance of $62 \%[16]$ while Watts and Meisel a male preponderance of $78 \%$. But Shahan et al had a female preponderance in their exhaustive study of 2424 patients.[17] In our study there was a male preponderance (64\%). Retrospective study of Zhang et al including 149 patients showed that most of the injuries (about $60 \%$ ) were of a trivial nature and ambulatory treatment was adequate.[18,19] These are in accordance with our findings.

The most common region affected are extremities and head.[10] Our study shows similar results (62.2\%). Our study mainly shows that elephants were the main miscreants. In fact, the Northern part of West Bengal experiences one of the highest levels of human elephant conflicts in Asia and kills on an average of 50 people each year. ${ }^{[20]}$ The occurrence of craniofacial injuries was found to be inversely related to that of extremity injuries. Craniofacial injuries were more in females and males of extreme ages. Injuries to the upper extremity around the elbow and upper forearm and midarm were quite common, perhaps as a result of trying to protect oneself from the wild animal. No poachers were victims in this study, and most occurred in the wee hours of dawn when the victims walked to the fields for work. A few cases also occurred in the residential areas also presumably because of deforestation. Most of the victims in our study were young men, almost all the attacks happened in far flung rural areas, most of attacks the took place in the early morning period, all the attacks were defensive, due to sudden encounters between victim and animal which followed in response to perceived threat to food, individual space or cubs by the animal. None of the attack was predatory which could be attributed to the fact that most of the attacks either terminated spontaneously or the surrounding people came to the rescue of the victim. All these observations are consistent with the findings of previous studies.[21,22]

In our study we observed that since most of the attacks occurred near foot hills, patients had to travel a long distance (10 to $40 \mathrm{Km}$ ) to reach the nearest medical centre and 65 to $150 \mathrm{Km}$ to reach our tertiary hospital. Besides the struggle by the victim at the time of attack makes the contaminated with dust, grass and also the oral cavity of the wild animals at times contaminated with numerous bacteria. All these factors make the wounds severely prone to infection. Thorough wound irrigation, extensive debridement of devitalized soft tissue was done as soon as possible. Even multiple debridement were done when required. Tetanus immunisation active and even passive at times was administered. Even anti-rabies vaccine was given at times 
mainly to the bite victims. Broad spectrum antimicrobials were administered in all such cases.

\section{CONCLUSIONS}

Hospitals close to the forests have to encounter such wild animal related injuries. Infrastructure development and training on the clinical spectrum of such injuries will help in dealing with the same. Though the forest authorities and personnel are quite efficient, early transportation through the dense forests to the nearest hospital will go a long way in dealing with this problem. Deforestation appears to be the chief reason behind the need for the wild animals to venture into human habitation in search of food and resulting in such conflicts. Measures to prevent deforestation are beyond the scope of our present study. More extensive studies are needed to reflect in a better and more quantitative manner the real magnitude of this clear and present danger.

\section{REFERENCES}

[1] State of forest report, WB, Forest Survey of India, Ministry of Environment, forests and climate change, Dehradun, fsi.nic.in/isfr2017/west-bengal-isfr-2017.pdf

[2] Wildlife Annual report 2017-2018, wildlifewing. Directorate of forests, Govt. of West Bengal, 2017-2018. https://www.wildbengal.com/admin.wildlife/upload/3 286Annual_Report \%.2017-2018.pdf

[3] Nelson A, Bidwell P, Sillero-Zubiri C. A review of human elephant conflict management strategies. People and Wildlife Initiative. Wildlife Conservation Research Unit, Oxford University, 2003.

[www.peopleandwildlife.org.uk/crmanuals/HumanElep hantConflictP\&WManual2003]

[4] Human Wildlife Conflict Manual: Wildlife Management Series, WWF-World Wide Fund for Nature (formerly World Wildlife Fund) Southern African Regional Programme Office (SARPO),

http://wwfpanda.org/....Wildlife-Management Series 2005.

[5] Smith PF, Meadowcroft AM, May DB. Treating mammalian bite wounds. J Clin Pharm Ther 2000;25 (2):85-99.

[6] Gilyoma JM, Mabula JB, Chalya PL. Animal-related injuries in a resource-limited setting: experiences from a Tertiary health institution in north western Tanzania. World J Emerg Surg 2013;8 (1):7.
[7] Rasouli MR, Saadat S, Haddadi M, et al. Epidemiology of injuries and poisonings in emergency departments in Iran. Public Health 2011;125 (10):727-33.

[8] Hendricks KJ, Adekoya N. Non-fatal animal related injuries to youth occurring on farms in the United States, 1998. Inj Prev 2001;7 (4):307-11.

[9] Erkal S, Gerberich SG, Ryan AD, et al. Animal-related injuries: a population-based study of a five-state region in the upper mid-west: regional rural injury study II. J Safety Res 2008;39 (4):351-63.

[10] Johns E, Farrant G, Civil I. Animal-related injury in an Urban New Zealand population. Injury: Int J Care Injured 2004;35 (12):1234-8.

[11] Temes RT, White JH, Ketai LH, et al. Head, face and neck trauma from large animal injury in New Mexico. J Trauma 1997;43 (3):492-5.

[12] Brett AU, Eric JD, Louis DH, et al. Patterns of maxillofacial injuries related to interaction with horses. J Oral Maxillofac Surg 2004;62 (6):693-6.

[13] Watts M, Meisel EM. Cattle associated trauma-a one year prospective study of all injuries. Injury 2011;42 (10):1084-7.

[14] Iba K, Wada T, Kawaguchi S, et al. Horse-related injuries in a thorough bred stabling area in Japan. Arch Orthop Trauma Surg 2001;121 (9):501-4.

[15] Yıldız M, Durukan P. Hayvanlara Bağlı Yaralanmalar. Firat Tıp Dergisi 2005;10 (1):24-6.

[16] Moini M, Peyvandi AA, Rasouli MR, et al. Pattern of animal-related injuries in Iran. Acta Med Iran 2011;49 (3):163-8.

[17] Shahan CP, Emmett K, Zarzaur BL. Large animal-related injury requiring hospital admission: injury pattern disparities. Injury 2012;43 (11):1898-902.

[18] Zhang QB, Zhang B, Zhang ZQ, et al. The epidemiology of cranio-facial injuries caused by animals in southerncentral China. J Craniomaxillofac Surg 2012;40 (6):506-9.

[19] Nogalski A, Jankiewicz L, Cwik G, et al. Animal-related injuries treated at the department of trauma and emergency medicine, medical university of Lublin. Ann Agric Environ Med 2007;14 (1):57-61.

[20] Radio-Telemetry Study of Elephants in Buxa Tiger Reserve and Adjoining Areas in North West Bengal, Asian Nature Conservation Foundation. [http://www.asiannature.org/....elephant-conflictrnitigation-pr-2] 2013.

[21] Bashir SA, Rasool A, Zaroo MI, et al. Bear maul and craniocerebral trauma in Kashmir valley. J Craniofac Surg 2013;24 (1):e2-5.

[22] Wani ML, Ahangar AG, Lone GN, et al. Vascular injuries after bear attacks: incidence, surgical challenges and outcome. J Emerg Trauma Shock 2011;4 (1):20-2. 